Check for updates

Cite this: New J. Chem., 2018 42,4474

Received 15th December 2017 Accepted 5th February 2018

DOI: 10.1039/c7nj04975g

rsc.li/njc

\section{Hydrothermal alkaline sulfite pretreatment in the delivery of fermentable sugars from sugarcane bagasse $\dagger$}

\author{
João Tavares, (D) *ab Rafał M. Łukasik, (D) ${ }^{b}$ Teresa de Paiva (D) and Flávio da Silva (D) ${ }^{a}$
}

This work aims to demonstrate the importance of hydrothermal alkaline sulfite pretreatment of sugarcane bagasse in the delivery of fermentable sugars. The pretreatment conditions, namely sodium sulfite loads $(5.0-10.0 \mathrm{wt} \%)$, temperatures $\left(140-160{ }^{\circ} \mathrm{C}\right)$ and reaction times $(30-60 \mathrm{~min})$, were tested according to the full factorial design of experiments. The employed pretreatment was characterized by high lignin removal (43-77 wt\%) and partial extraction of xylans (up to $25.0 \mathrm{wt} \%$ ), mainly by cleavage of acetyl and arabinosyl groups. After $72 \mathrm{~h}$ of enzymatic hydrolysis with $10 \mathrm{FPU}$ (filter paper unit) cellulase and $10 \mathrm{CBU}$ (cellobiose unit) $\beta$-glucosidase per $\mathrm{g}$ of pretreated bagasse, the conversion of the carbohydrate-enriched substrates was in the range of 51 to $80 \mathrm{~mol} \%$ for cellulose and 45 to $71 \mathrm{~mol} \%$ for xylans. The best hydrothermal alkaline sulfite pretreatment conditions $\left(10.0\right.$ wt $\%$ sulfite load, $150{ }^{\circ} \mathrm{C}$ and $45 \mathrm{~min}$ ) were found to be highly efficient for the delivery of fermentable sugars with a yield as high as $40.4 \pm 1.9 \mathrm{~g}$ for $100 \mathrm{~g}$ native bagasse.

\section{Introduction}

Due to the negative environmental impact, fossil resources are considered as unsustainable. ${ }^{1}$ Thus, in the last few decades a growing demand for alternative and renewable energy sources has been observed. ${ }^{2}$ Among the several types of renewable energy resources available, biomass, especially lignocellulosic biomass, is one of the most relevant natural carbon feedstock. Lignocellulosic biomass is an abundant and generally low cost raw material and once it is non-food and non-feed competitive, it is an important feedstock for production of biofuels and value-added commodities. ${ }^{3}$ Agro-industrial wastes and residues can be excellent examples of such biomass, because nowadays they are mostly used as a solid fuel. Therefore, smarter and more valuable valorization of such residues would bring some advantages from the societal, environmental and economic points of view.

Sugarcane bagasse is one of the relevant agro-industrial residues, as it is the leftover of sugar and ethanol industries used chiefly for energy purposes. Sugarcane bagasse is also one of the most abundant lignocellulosic feedstocks of high

\footnotetext{
${ }^{a}$ University of São Paulo, Engineering School of Lorena, Estrada Municipal do Campinho $s / n^{o}$, Campinho, Lorena-SP, 12602-810, Brazil

${ }^{b}$ National Laboratory for Energy and Geology (LNEG, I. P.), Unit of Bioenergy,

Estrada do Paço do Lumiar 22, 1649-038 Lisbon, Portugal.

E-mail: joao.tavares@lneg.pt; Tel: +35 1964898069

$\dagger$ Electronic supplementary information (ESI) available. See DOI: 10.1039/ c7nj04975g
}

potential, which can be used for bioenergy and bioproducts. ${ }^{4}$ Sugarcane bagasse, as other lignocellulosic feedstocks, is constituted by the biopolymers of cellulose, hemicellulose and lignin, which are interlinked and form a resistant and recalcitrant structure against microbiological and chemical agents. Therefore, to provide an effective fractionation of this complex matrix and to deliver upgradable saccharides, an appropriate biomass preprocessing step, called pretreatment, is required. ${ }^{5}$ In recent years, various pretreatment methods have been developed and have been examined extensively. Among them are those including non-catalytic pretreatments, e.g. steam or hot water, and biological (e.g. fungi), or chemical pretreatments with acids, alkalis, organic solvents or ionic liquids. ${ }^{5-11}$ Although there is a significant advance in the development of more efficient, environmentally acceptable and economically feasible processes, there is still a strong need for effective pretreatment technologies that could enhance the economics of biomass valorization. One of the promising processes is the use of sulfur-containing compounds, and some recent reports ${ }^{12}$ showed encouraging results for pretreatment of hardwoods, ${ }^{13}$ softwoods,${ }^{14}$ corn stalk, ${ }^{15}$ switchgrass ${ }^{16}$ and other feedstocks. The pretreated feedstocks generally are characterized by high hydrolysis potential, as the enzymatic conversion rate can be as high as $90 \%$. One of the reasons for this might be the fact that during the acid sulfite pretreatment, most of hemicellulose is hydrolyzed together with a vast part of lignin. In addition, the reduction of cellulose crystallinity is observed. However, to minimize losses of hemicellulose and cellulose, and to prevent the formation of fermentation inhibitors, 